\title{
Foramen Magnum Orientation and Its Association with Cervical Lordosis: A Model for Reconstructing Cervical Curvature in Archeological and Extinct Hominin Specimens
}

\author{
Ella Been ${ }^{1,2 *}$, Sara Shefi' ${ }^{1}$, Lisa Raviv Zilka ${ }^{3,4}$, Michalle Soudack ${ }^{3,4}$ \\ ${ }^{1}$ Department of Anatomy and Anthropology, Sackler Faculty of Medicine, Tel Aviv University, Tel Aviv, Israel \\ ${ }^{2}$ Department of Physical Therapy, Faculty of Health Professions, Ono Academic College, Kiryat Ono, Israel \\ ${ }^{3}$ Pediatric Imaging, Edmond and Lily Safra Children's Hospital, Tel Hashomer, Israel \\ ${ }^{4}$ Sackler Faculty of Medicine, Tel Aviv University, Tel Aviv, Israel \\ Email: ${ }^{*}$ beenella@post.tau.ac.il
}

Received 16 April 2014; revised 13 May 2014; accepted 4 June 2014

Copyright (C 2014 by authors and Scientific Research Publishing Inc. This work is licensed under the Creative Commons Attribution International License (CC BY). http://creativecommons.org/licenses/by/4.0/ c) (i) Open Access

\section{Abstract}

The cranial base is located at a critical intersection between the vertebral spine, the brain, the respiratory system and the mastication apparatus. Therefore it can provide an insight into the evolution of the head and neck in functional and phylogenetic contexts. However, the relationship between cranial base anatomy and cervical spine alignment has not been explored deeply. Therefore the aim of this research is to study the relationship between the orientation of the foramen magnum and the degree of cervical lordosis. Based on this relationship we developed six models which enable reconstruction of the cervical lordosis angle in archeological material and in extinct hominins. 74 adult lateral cervical radiographs were examined. The orientation of the foramen magnum and the angle of the cervical lordosis were measured on each radiograph. Foramen magnum orientation positively correlates with cervical lordosis angles: moderate to high correlation was found between foramen magnum orientation and the total cervical lordosis $(0.716<\mathrm{r}<$ 0.612); moderate correlation was also found between foramen magnum orientation and the upper cervical lordosis $(0.626<\mathrm{r}<0.562)$; and only weak correlation was found with the lower cervical lordosis $(0.306<r<0.101)$. Assuming that the positive correlation between foramen magnum orientation and cervical lordosis can be applied to all bipedal hominins, cranial base morphology can provide an insight to the degree of the cervical lordosis of archeological material and of extinct hominin.

${ }^{*}$ Corresponding author.

How to cite this paper: Been, E., Shefi, S., Zilka, L. R., \& Soudack, M. (2014). Foramen Magnum Orientation and Its Association with Cervical Lordosis: A Model for Reconstructing Cervical Curvature in Archeological and Extinct Hominin Specimens. Advances in Anthropology, 4, 133-140. http://dx.doi.org/10.4236/aa.2014.43017 


\section{Keywords}

\section{Posture, Cervical Spine, Radiology, Basicranium}

\section{Introduction}

The cranial base is located at a critical intersection between of the vertebral spine, the brain, the respiratory system and the mastication apparatus. Therefore it is frequently consulted source into the evolution of the head and neck in functional and phylogenetic contexts (Chan, 2007; Kimbel \& Rak, 2010). The position and orientation of the foramen magnum differ between humans and non human hominoids (Dean \& Wood, 1981, 1982; Aiello \& Dean, 1990; Luboga \& Wood, 1990; Schaefer, 1999; Russo \& Kirk, 2013). Humans present anterior foramen magnum, while apes present more posterior ones. This difference in the position of the foramen magnum probably reflects head position and locomotive posture (Dart, 1925; Broom, 1938; Le Gros Clark, 1954; Russo \& Kirk, 2013), although the nature of this relationship has not been fully established (Ashton \& Zuckerman, 1956; Moore et al., 1973; Masters et al., 1991). Non human hominoids also lack the pronounced cervical lordosis seen in humans. Modern humans have a well-defined cervical lordosis that helps situate the head above the thorax in erect posture, whereas the head of quadrupedal apes is situated anterior to the thorax, with a slight cervical lordosis (Schultz, 1961; Filler, 2007).

Current knowledge of the evolution of foramen magnum orientation is based on cranial fossil records of extinct and extant hominoids. Unlike the osseous nature of the skull, the cervical lordosis is comprised of both osseous (vertebrae) and soft tissue (intervertebral discs, and spinal ligaments) elements. However, for archeological material and extinct hominin specimens, only the vertebrae are available and therefore the fossil and archeopaleontological record is mute on the evolvement of the cervical lordosis.

Very few researchers have explored the relationship between cranial base anatomy and cervical spine posture (Solow \& Sandham, 2002). If these structures are indeed related than it would provide us with an insight as to the position of the head on the cervical column in hominins (Kimbel \& Rak, 2010), and also allow reconstruction of the cervical lordosis from osseous specimens.

Therefore the aim of this research is to study the relationship between the orientation of the foramen magnum and the degree of cervical lordosis. Based on this relationship a model will be developed to enable the reconstruction the cervical lordosis angle in archeological material and in extinct hominins.

\section{Materials and Methods}

A total of 74 lateral cervical radiographs of patients aged 20 - 50 years were examined (36 males and 38 females). All radiographs were performed at the Chaim Sheba Medical Center, Tel Aviv, Israel. Inclusion criteria were as follows: upright radiograph, all cervical vertebrae and cranial base were visualized and the radiograph was in a true lateral position. Exclusion criteria included any radiographic abnormality: degenerative changes, reduced disc height, fractures and evidence of scoliosis on the associated anterior posterior view. Standard lateral cervical radiographs are obtained with subjects standing comfortably with knees straight and arms resting on the side of the body. The subjects are instructed to stand straight with a forward gaze. To eliminate the possibility of incorrect head posture only radiographs with palatine plane close to the horizontal plane $\left( \pm 10^{\circ}\right)$ were included (in accordance with Barbera, 2009). The study was approved by the Helsinki committee of the Chaim Sheba Medical Center.

\section{Measurements}

On each radiograph the following lines were drawn (Figure 1):

- Horizontal plane (HP): parallel to the superior end of the radiograph.

- Foramen magnum (FM): between the basion and the opisthion.

- Palatine bone plane (PP): the plane formed by the palatine bone

- Third cervical vertebra (C3): parallel to the inferior endplate of C3.

- Seventh cervical vertebra (C7): parallel to the inferior endplate of C7.

Based on these lines one of us (SS) measured the following angles: 


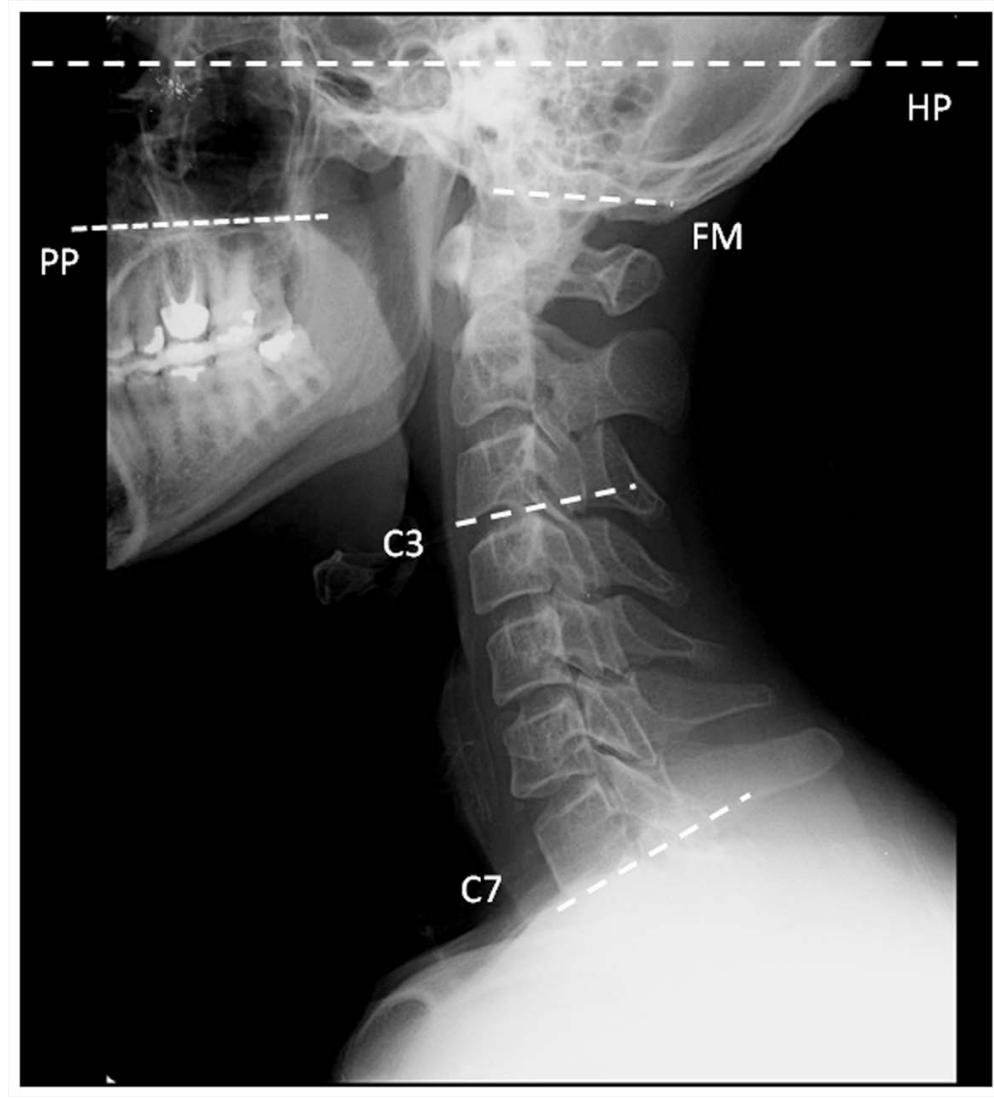

Figure 1. Lateral radiograph of the skull and cervical spine showing the lines drawn on each radiograph. HP, horizontal plane; FM, foramen magnum; PP, palatine bone plane; $\mathrm{C} 3$, third cervical vertebra; $\mathrm{C}$, seventh cervical vertebra.

- FM-HP: between the foramen magnum and the horizontal plane. Positive values indicate that the FM is facing anteriorly while negative values indicate that it faces posteriorly in relation to the horizontal plane.

- FM-PP: between the palatine bone plane and the foramen magnum. Positive values indicate that the FM is facing anteriorly while negative values indicate that it faces posteriorly in relation to the palatine plane.

- PP-HP: between the palatine bone plane and the horizontal plane.

- Total cervical lordosis (FM-C7): between the foramen magnum and C7.

- Upper cervical lordosis (FM-C3): between the foramen magnum and C3.

- Lower cervical lordosis: between C3-C7.

Descriptive statistics was calculated using Excel 2007 (Microsoft Corporation, Redmond, Washington, USA). Correlation analysis and regression equations were obtained using bivariate fit models (fit $\mathrm{Y}$ by X, JMP Statistics Software, SAS Institute, Cary, NC). To assess the intra-observer reliability of the measurements, 13 radiographs were measured twice, one week apart. The intraclass correlation coefficients (ICC) were between $0.72<$ ICC $<0.98(p<0.0001)$ for the six cervical angular measurements.

\section{Results}

The mean total cervical lordosis (FM-C7, $37.3^{\circ} \pm 9.8^{\circ}$ ) is composed of the upper cervical lordosis (FM-C3, 26. $4^{\circ}$ $\pm 7.9^{\circ}$ ), and lower cervical lordosis (C3-C7, $11.3^{\circ} \pm 8.8^{\circ}$ ) indicating that the upper part of the cervical spine contributes over two thirds of the total lordosis while the lower cervical lordosis contributes less than one third (Table 1). The orientation of the foramen magnum to the horizontal plane is $10.2^{\circ} \pm 6.7^{\circ}$, meaning that the foramen magnum is slightly angled anteriorly (ventral), and not only caudally (downwards). Similar orientation is shown between the foramen magnum to the palatine plane (FM-PP, $6.3 \pm 6.5$ ) (Table 1). High correlation exists between the FM-HOR and FM-PP. The upper cervical lordosis (FM-C3) of females is higher than that of males, 
while the lower cervical lordosis (C3-C7) of males is higher than that of females (Table 2). For the remaining variables examined, there were no other significant differences between males and females.

The orientation of the foramen magnum to the horizontal plane (FM-HR) positively correlates with all cervical lordosis angles (total, upper and lower. Figure 2, Table 3). It shows moderate to high correlation to the total

Table 1. Angular measurements of the cervical spine and skull (degrees) of the entire population. Positive values indicate lordosis, negative values indicate kyphosis.

\begin{tabular}{ccccc}
\hline Angle & Average & Standard deviation & Range & Previously published values \\
FM-HP & 10.2 & 6.7 & $-5.2 ; 23.6$ & $8.2 \pm 6.5(-5 ; 21)^{*}$ \\
FM-PP & 6.3 & $6.4 \pm 6.5(-12 ; 16)^{\wedge}$ & 9.9 (modified $^{*}$ \\
4.5 (modified $^{\wedge}$ \\
HP-PP & 2.4 & 6.5 & $-6.3 ; 23.0$ & $-1.7 \pm 5.0(9 ;-13)^{*}$ \\
FM-C7 & 37.3 & 4.4 & $-8.7 ; 10.9$ & $-0.97 \pm 5.0(9.8 ;-13.4)^{\wedge}$ \\
FM-C3 & 26.4 & 9.8 & $15.5 ; 66.2$ & $40.0 \pm 9.7^{\S}$ \\
C3-C7 & 11.2 & 7.9 & $1.8 ; 44.0$ & $-5.3 ; 33.3$ \\
\hline
\end{tabular}

FM-HP, between the foramen magnum and the horizontal plane; FM-PP, between the palatine bone plane and the foramen magnum; FM-HP, between the foramen magnum and the horizontal plane; FM-PP, between the palatine bone plane and the foramen magnum; PP-HP, between the palatine bone plane and the horizontal plane; FM-C7, total cervical lordosis; FM-C3, upper cervical lordosis; C3-C7, lower cervical lordosis. "Barbera, 2009. ${ }^{\wedge}$ Madsen et al., 2008. ${ }^{\S}$ Hardacker et al., 1997.

Table 2. Comparison between Angular measurements of males and females.

\begin{tabular}{cccccc}
\hline & Males & & Females & & T test between males and females \\
\hline Angle & Average & Standard deviation & Average & Standard deviation & $p$ value \\
\hline FM-HP & 9.2 & 6.2 & 11.1 & 6.8 & 0.2 \\
FM-PP & 4.3 & 5.4 & 7.4 & 7.0 & 0.1 \\
HP-PP & 2.6 & 6.1 & 2.3 & 3.1 & 0.97 \\
FM-C7 & 37.6 & 9.7 & 36.8 & 10.0 & 0.72 \\
FM-C3 & 23.9 & 7.6 & 28.6 & 7.6 & $\underline{\mathbf{0 . 0 0 9}}$ \\
C3-C7 & 11.2 & 9.1 & 8.7 & 8.7 & $\underline{\mathbf{0 . 0 0 8}}$ \\
\hline
\end{tabular}

FM-HP, between the foramen magnum and the horizontal plane; FM-PP, between the palatine bone plane and the foramen magnum; FM-HP, between the foramen magnum and the horizontal plane; FM-PP, between the palatine bone plane and the foramen magnum; PP-HP, between the palatine bone plane and the horizontal plane; FM-C7, total cervical lordosis; FM-C3, upper cervical lordosis; C3-C7, lower cervical lordosis.

Table 3. Pearson correlation coefficient (r, lower left) and level of significance ( $p$, upper right) between measurements.

\begin{tabular}{|c|c|c|c|c|c|c|}
\hline Measurement & FM-HP & FM-PP & HP-PP & FM-C7 & FM-C3 & C3-C7 \\
\hline FM-HP & 1.0 & $* *$ & $*$ & $* *$ & $* *$ & $*$ \\
\hline FM-PP & 0.78 & 1.0 & * & ** & $* *$ & NS \\
\hline HP-PP & 0.35 & -0.36 & 1.0 & NS & NS & $*$ \\
\hline FM-C7 & 0.72 & 0.61 & 0.10 & 1.0 & ** & ** \\
\hline FM-C3 & 0.56 & 0.63 & -0.05 & 0.55 & 1.0 & * \\
\hline C3-C7 & 0.31 & 0.10 & 0.16 & 0.62 & -0.26 & 1.0 \\
\hline
\end{tabular}

FM-HP, between the foramen magnum and the horizontal plane; FM-PP, between the palatine bone plane and the foramen magnum; FM-HP, between the foramen magnum and the horizontal plane; FM-PP, between the palatine bone plane and the foramen magnum; PP-HP, between the palatine bone plane and the horizontal plane; FM-C7, total cervical lordosis; FM-C3, upper cervical lordosis; C3-C7, lower cervical lordosis; NS, non significant; ${ }^{*} p$ $<0.05 ;{ }^{* *} p<0.01$. 
FM - HP
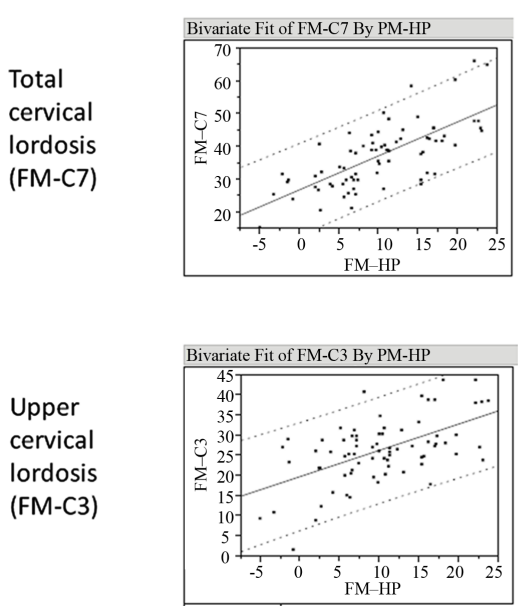

FM - PP
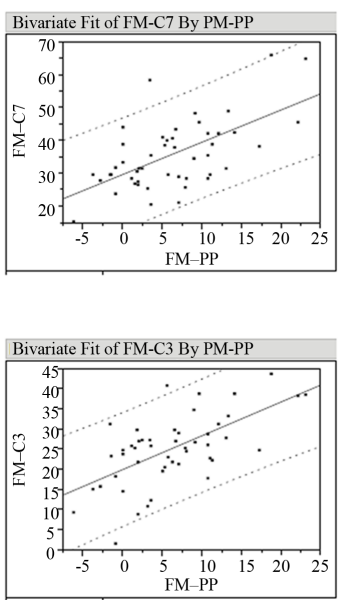

Figure 2. Bivariate fit of the cervical lordosis angles by foramen magnum orientation. Solid line, linear fit; dashed line, 95\% confidence interval.

cervical lordosis and to the upper cervical lordosis, and weak correlation with the lower cervical lordosis. The orientation of the foramen magnum to the palatine plane (FM-PP) also correlates with the cervical lordosis measurements. Based on these correlations we developed four regression models for calculating total (FM-C7) and upper (FM-C3) cervical lordosis (Table 4, Figure 2). All four models explain between one third to half of the variability found in cervical lordosis in modern humans $\left(0.315<\mathrm{R}^{2}<0.512\right)$ and their root mean square error is between $6.59^{\circ}-8.36^{\circ}$.

As the upper cervical lordosis of females was higher than that of males, and the ANCOVA test revealed significant difference in slope and intercept between the regression lines of males and females, we developed two more regression models for calculating upper cervical lordosis, one based solely on males and the other one on females (Table 4).

\section{Discussion}

We found a significant positive correlation between the inclination of the foramen magnum and the cervical lordosis in a modern human sample. These correlations indicate that foramen magnum orientation can be used as an indicator to the degree of cervical lordosis. Both measurements for foramen magnum orientation-in relation to the horizontal plane (FM-HOR) and in relation to the palatine plane (FM-PP) are applicable for predicting cervical lordosis as both were found to have positive correlation with the cervical lordosis.

Altogether we developed six models: four models for calculating cervical lordosis (total and upper) based on the entire modern human population, and two different models for calculating upper cervical lordosis for males and for females. Four out of the six models are extrinsic to the skull and are based on the orientation of the foramen magnum in relation to the horizontal plane. Two models are intrinsic to the skull, and are based on the orientation of the foramen magnum in relation to the palatine plane. To the best of our knowledge, this is the first time a reliable method for reconstructing cervical lordosis in osseous material is presented.

For example, we reconstructed cervical lordosis angles for a modern human specimen from the osteological collection of Tel Aviv University (Israel). Using the lateral radiograph of the specimen's skull we measured FM-HP between the foramen magnum and the Frankfurt horizontal plane $\left(12.6^{\circ}\right)$ and FM-PP between the foramen magnum and the palatine bone plane $\left(9^{\circ}\right)$ (Figure 3). Based on these measurements and the six models developed in this study (Table 4) we calculated the cervical lordosis for the modern human specimen (Table 5). The calculated total cervical lordosis (FM-C7) for this skull is $38.7^{\circ}-39.8^{\circ}\left( \pm 8.3^{\circ}\right)$, and upper cervical lordosis (FM-C3) is $26.2^{\circ}-29.3^{\circ}\left( \pm 6.9^{\circ}\right)$. These results are very close to the average cervical lordosis of living modern humans $\left(\mathrm{FM}-\mathrm{C} 7=37.3^{\circ} \pm 9.8^{\circ}\right.$; FM-C3 $=26.4^{\circ} \pm 7.9^{\circ}$ ). We suggest that if the skull's gender is known, than upper cervical lordosis should be calculated with the specific model (males/females). If the gender is unknown, than the general regression model (based on the pooled sample of males and females) should be used. 


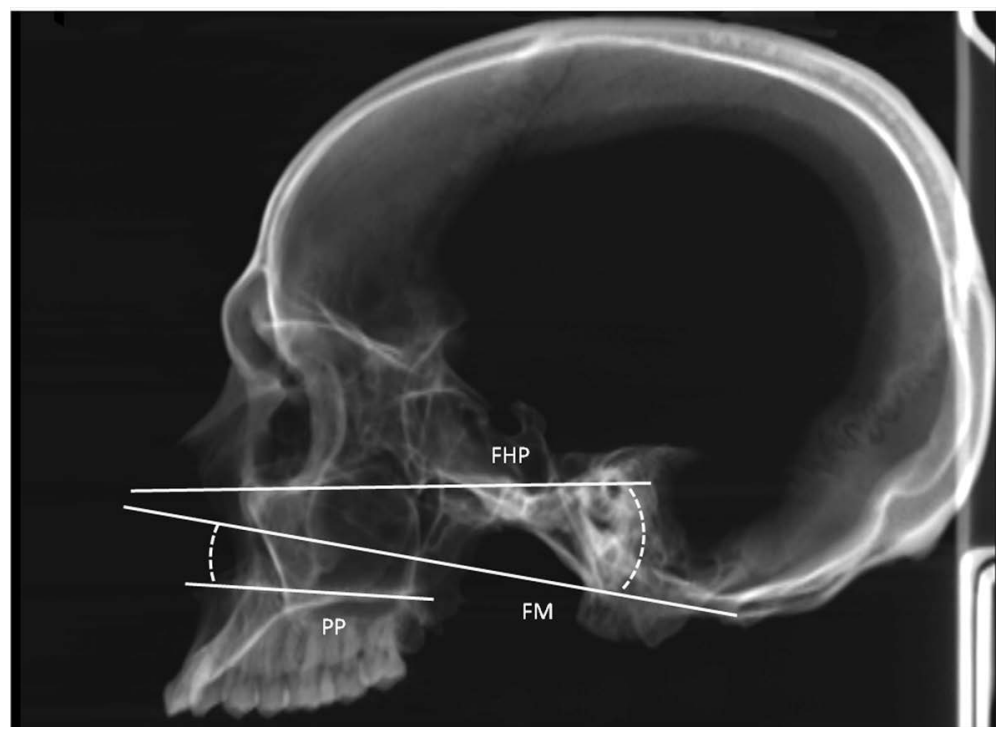

Figure 3. Lateral radiograph of a modern human skull from the osteological collection of Tel Aviv University showing the angles measured for calculating cervical lordosis. FHP, Frankfurt horizontal plane; FM, foramen magnum; PP, palatine bone plane.

Table 4. Regression models for calculating cervical lordosis based on foramen magnum orientation.

\begin{tabular}{|c|c|c|c|c|}
\hline Model & Regression equation & $\mathrm{R}^{2}$ & Significance & $\begin{array}{l}\text { Root mean square } \\
\text { error }\end{array}$ \\
\hline $\begin{array}{l}\text { FM-C7 based on FM-HP } \\
\text { (males and females) }\end{array}$ & FM-C7 $=26.92+1.03 *$ FM-HP & 0.512 & $<0.0001$ & 6.92 \\
\hline $\begin{array}{l}\text { FM-C7 based on FM-PP } \\
\text { (males and females) }\end{array}$ & FM-C7 $=29.85+0.98 * F M-P P$ & 0.374 & $<0.0001$ & 8.36 \\
\hline $\begin{array}{l}\text { FM-C3 based on FM-HP } \\
\text { (males and females) }\end{array}$ & FM-C3 $=19.82+0.65 * F M-H P$ & 0.315 & $<0.0001$ & 6.59 \\
\hline $\begin{array}{l}\text { FM-C3 based on FM-PP } \\
\text { (males and females) }\end{array}$ & FM-C3 $=20.05+0.84 * F M-P P$ & 0.390 & $<0.0001$ & 6.90 \\
\hline $\begin{array}{l}\text { FM-C3 based on FM-HP } \\
\text { (males only) }\end{array}$ & FM-C3 $=17.62+0.68 *$ FM-HP & 0.310 & $<0.001$ & 6.30 \\
\hline $\begin{array}{l}\text { FM-C3 based on FM-HP } \\
\text { (females only) }\end{array}$ & FM-C3 $=22.65+0.53 *$ FM-HP & 0.232 & $<0.001$ & 6.71 \\
\hline
\end{tabular}

FM-HP, between the foramen magnum and the horizontal plane; FM-PP, between the palatine bone plane and the foramen magnum; FM-HP, between the foramen magnum and the horizontal plane; FM-PP, between the palatine bone plane and the foramen magnum; PP-HP, between the palatine bone plane and the horizontal plane; FM-C7, total cervical lordosis; FM-C3, upper cervical lordosis; C3-C7, lower cervical lordosis.

Table 5. Reconstructed cervical lordosis angles for one modern human skull.

\begin{tabular}{ccc}
\hline Model & Regression equation & Calculated cervical lordosis \\
\hline FM-C7 based on FM-HP & FM-C7 $=26.92+1.03 * 12.6$ & $39.8^{\circ}$ \\
FM-C7 based on FM-PP & FM-C7 $=29.85+0.98 * 9$ & $38.7^{\circ}$ \\
FM-C3 based on FM-HP & FM-C3 $=19.82+0.65 * 12.6$ & $28.0^{\circ}$ \\
FM-C3 based on FM-PP & FM-C3 $=20.05+0.84 * 9$ & $27.6^{\circ}$ \\
$\begin{array}{c}\text { FM-C3 based on FM-HP } \\
\text { (males only) } \\
\text { FM-C3 based on FM-HP } \\
\text { (females only) }\end{array}$ & FM-C3 $=17.62+0.68 * 12.6$ & $26.2^{\circ}$ \\
\hline
\end{tabular}


Cervical posture has been related to the shape of the cranium and the face, subjects with a long cranium (dolichocephalic) have a straight, long, forwardly inclined cervical column, whereas subjects with a short cranium (brachycephalic) usually have increased lordosis of the spine (Bench, 1963). Cervical posture has also been related to mandibular length, as longer mandibles correlates with a straighter cervical column and vice versa (Özbek \& Köklü, 1993; Festa et al., 2003; Tecco \& Festa, 2007).

Deviations in cervical lordosis and head posture in modern humans are associated with compromised oral respiration, obstructed breathing passage, dysfunction of the cranio-cervical muscles, and cervical pain radiating down the back and up as high as the vertex of the cranium (Linder-Aronson, 1979; Vig et al., 1980; Solow et al., 1984; Hellsing et al., 1986; Chan, 2007). Establishing cervical lordosis for archeological specimens and extinct hominins based on our models may provide insights on both the evolution of cervical lordosis and on modern health related issues.

When considering our results, we must address several aspects. First, the orbits are not included in the standard lateral cervical radiograph in order to minimize radiation effects. This prevented us from measuring the Frankfurt horizontal plane. The Frankfurt horizontal plane is considered the gold standard for skull orientation in osseous material and in the skulls of extinct hominins. Instead, we used two planes: 1) the true horizontal plane, and 2) the palatine bone plane. The similarity in the calculated lordosis between these two planes (Table 5) renders them reliable in reconstructing cervical lordosis. This is not surprising due to the high correlation found in our research between the orientation of the foramen magnum to the true horizontal plane (FM-HP) and the orientation of the foramen magnum to the palatine bone plane (FM-PP, $r=0.78$ ). Second, although we excluded abnormal radiographs we cannot accurately define the degree of symptoms in this sample of modern humans. To ensure that their cervical lordosis is within normal range for modern humans we compared our results with other publications. The close similarity between the cervical lordosis values found in the current study and in previous studies indicates that our values of cervical lordosis angles are similar to that of healthy individuals (Hardacker et al., 1997; Madsen et al., 2008; Barbera, 2009).

\section{Conclusion}

In conclusion, we found positive correlations between the orientation of the foramen magnum to that of the total cervical lordosis and to the upper cervical lordosis. Based on these correlations we developed six models for calculating cervical lordosis in osseous material where soft tissues are absent (as in archeological and extinct hominin specimens). In a future study we attempt to reconstruct cervical lordosis of archeological populations and extinct hominins based on cranial morphology.

\section{Acknowledgements}

The authors thank Prof. Yoel Rak and Mr. Alon Barash for their help. Drs. Been and Shefi contributed equally to this work.

\section{References}

Aiello, L., \& Dean, C. (1990) An Introduction to Human Evolutionary Anatomy. Waltham: Academic Press, Harcourt Brace and Co.

Ashton, E. H., \& Zuckerman, S. (1956) Age Changes in the Position of the Foramen Magnum in Hominids. Proceedings of the Zoological Society of London, 126, 315-325. http://dx.doi.org/10.1111/j.1096-3642.1956.tb00440.x

Barbera, A. L., Sampson, W. J., \& Townsend, G. C. (2009) An Evaluation of Head Position and Craniofacial Reference Line Variation. Homo, 60, 1-28. http://dx.doi.org/10.1016/j.jchb.2008.05.003

Bench, R. W. (1963) Growth of the Cervical Vertebrae as Related to Tongue, Face, and Denture Behavior. American Journal of Orthodontics, 49, 183-214. http://dx.doi.org/10.1016/0002-9416(63)90050-2

Broom, R. (1938) The Pleistocene Anthropoid Apes of South Africa. Nature, 142, 377-379. http://dx.doi.org/10.1038/142377a0

Chan, C. A. (2007) A Review of the Clinical Significance of the Occlusal Plane: Its Variation and Effect on Head Posture. International College of Craniomandibular Orthopedics (ICCMO) Anthology, 8, 1-63.

Dart, R. (1925) Australopithecus Africanus: The Man-Ape of South Africa. Nature, 115, 195-199. http://dx.doi.org/10.1038/115195a0 
Dean, M. C., \& Wood, B. A. (1981) Metrical Analysis of the Basicranium of Extant Hominoids and Australopithecus. American Journal of Physical Anthropology, 54, 63-71. http://dx.doi.org/10.1002/ajpa.1330540109

Dean, M. C., \& Wood, B. A. (1982) Basicranial Anatomy of Plio-Pleistocene Hominids from East and South Africa. American Journal of Physical Anthropology, 59, 157-174. http://dx.doi.org/10.1002/ajpa.1330590206

Festa, F., Tecco, S., Dolci, M. et al. (2003) Relationship between Cervical Lordosis and Facial Morphology in Caucasian Women with Skeletal Class II Malocclusion: A Cross-Sectional Study. Journal of Craniomandibular Practice, 21, 121129.

Filler, A. G. (2007). Emergence and Optimization of Upright Posture among Hominiform Hominoids and the Evolutionary Pathophysiology of Back Pain. Neurosurgical Focus, 23, 1-6.

Hardacker, J. W., Shuford, R. F., Capicotto, P. N., \& Pryor, P. W. (1997). Radiographic Standing Cervical Segmental Alignment in Adult Volunteers without Neck Symptoms. Spine, 22, 1472-1479. http://dx.doi.org/10.1097/00007632-199707010-00009

Hellsing, E., Forsberg, C. M., Linder-Aronson, S., \& Sheikholeslam, A. (1986). Changes in Postural EMG Activity in the Neck and Masticatory Muscles Following Obstructions of the Nasal Airways. European Journal of Orthodontics, 8, 247-253. http://dx.doi.org/10.1093/ejo/8.4.247

Kimbel, W. H., \& Rak, Y. (2010). The Cranial Base of Australopithecus afarensis: New Insights from the Female Skull. Philosophical Transactions of the Royal Society B: Biological Sciences, 365, 3365-3376. http://dx.doi.org/10.1098/rstb.2010.0070

Le Gros Clark, W. E. (1954). Reason and Fallacy in the Study of Fossil Man. Advanced Science of London, 43, 1-13.

Linder-Aronson, S. (1979). The Growth in the Sagittal Depth of the Bony Nasopharynx in Relation to Some Other Facial Variables. In J. A. McNamara (Ed.), Naso-Respiratory Function and Craniofacial Growth, Monograph 9, Craniofacial Growth Series (2nd ed., pp. 27-40). Ann Arbor: Center for Human Growth and Development, University of Michigan.

Luboga, S. A., \& Wood, B. A. (1990). Position and Orientation of the Foramen Magnum in Higher Primates. American Journal of Physical Anthropology, 81, 67-76. http://dx.doi.org/10.1002/ajpa.1330810108

Madsen, D. P., Sampson, W. J., \& Townsend, G. C. (2008). Craniofacial Reference Plane Variation and Natural Head Position. European Journal of Orthodontics, 30, 532-540. http://dx.doi.org/10.1093/ejo/cjn031

Masters, A. V., Falk, D., \& Gage, T. B. (1991). Effects of Age and Gender on the Location and Orientation of the Foramen Magnum in Rhesus Macaques (Macaca mulatta). American Journal of Physical Anthropology, 86, 75-80.

http://dx.doi.org/10.1002/ajpa.1330860106

Moore, W. J., Adams, L. M., \& Lavelle, C. L. B. (1973). Head Posture in the Hominoidea. Journal of Zoology, 169, 409-416. http://dx.doi.org/10.1111/j.1469-7998.1973.tb03120.x

Özbek, M. M., \& Köklü, A. (1993). Natural Cervical Inclination and Craniofacial Structure. American Journal of Orthodontics and Dentofacial Orthopedics, 104, 584-591. http://dx.doi.org/10.1016/S0889-5406(05)80442-1

Russo, G. A., \& Kirk, E. C. (2013). Foramen Magnum Position in Bipedal Mammals. Journal of Human Evolution, 65, 656-670. http://dx.doi.org/10.1016/j.jhevol.2013.07.007

Schaefer, M. S. (1999). Foramen Magnum-Carotid Foramina Relationship: Is It Useful for Species Designation? American Journal of Physical Anthropology, 110, 467-471.

http://dx.doi.org/10.1002/(SICI)1096-8644(199912)110:4<467::AID-AJPA7>3.0.CO;2-R

Solow, B., Siersbæk-Nielsen, S., \& Greve, E. (1984). Airway Adequacy, Head Posture and Craniofacial Morphology. American Journal of Orthodontics, 86, 214-223. http://dx.doi.org/10.1016/0002-9416(84)90373-7

Solow, B., \& Sandham, A. (2002). Cranio-Cervical Posture: A Factor in the Development and Function of the Dentofacial Structures. European Journal of Orthodontics, 24, 447-456. http://dx.doi.org/10.1093/ejo/24.5.447

Schultz, A. H. (1961). Vertebral Column and Thorax. In H. Hofer, A. H. Schultz, \& D. Stark (Eds.), Primatologia (Vol. 4, pp. 1-46). Basel: Karger.

Tecco, S., \& Festa, F. (2007). Cervical Spine Curvature and Craniofacial Morphology in an Adult Caucasian Group: A Multiple Regression Analysis. European Journal of Orthodontics, 29, 204-209. http://dx.doi.org/10.1093/ejo/cj1061

Vig, P. S., Showfety, K., \& Phillips, C. (1980). Experimental Manipulation of Head Posture. American Journal of Orthodontics, 77, 258-268. http://dx.doi.org/10.1016/0002-9416(80)90081-0 
Scientific Research Publishing (SCIRP) is one of the largest Open Access journal publishers. It is currently publishing more than 200 open access, online, peer-reviewed journals covering a wide range of academic disciplines. SCIRP serves the worldwide academic communities and contributes to the progress and application of science with its publication.

Other selected journals from SCIRP are listed as below. Submit your manuscript to us via either submit@scirp.org or Online Submission Portal.
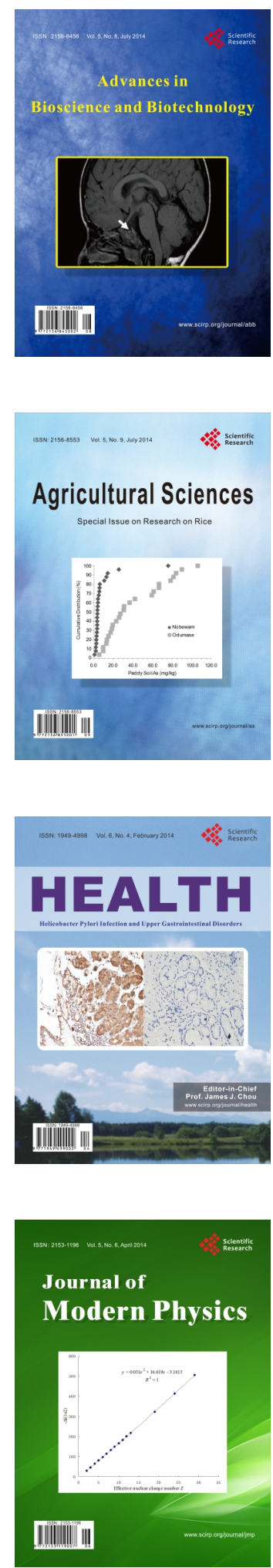
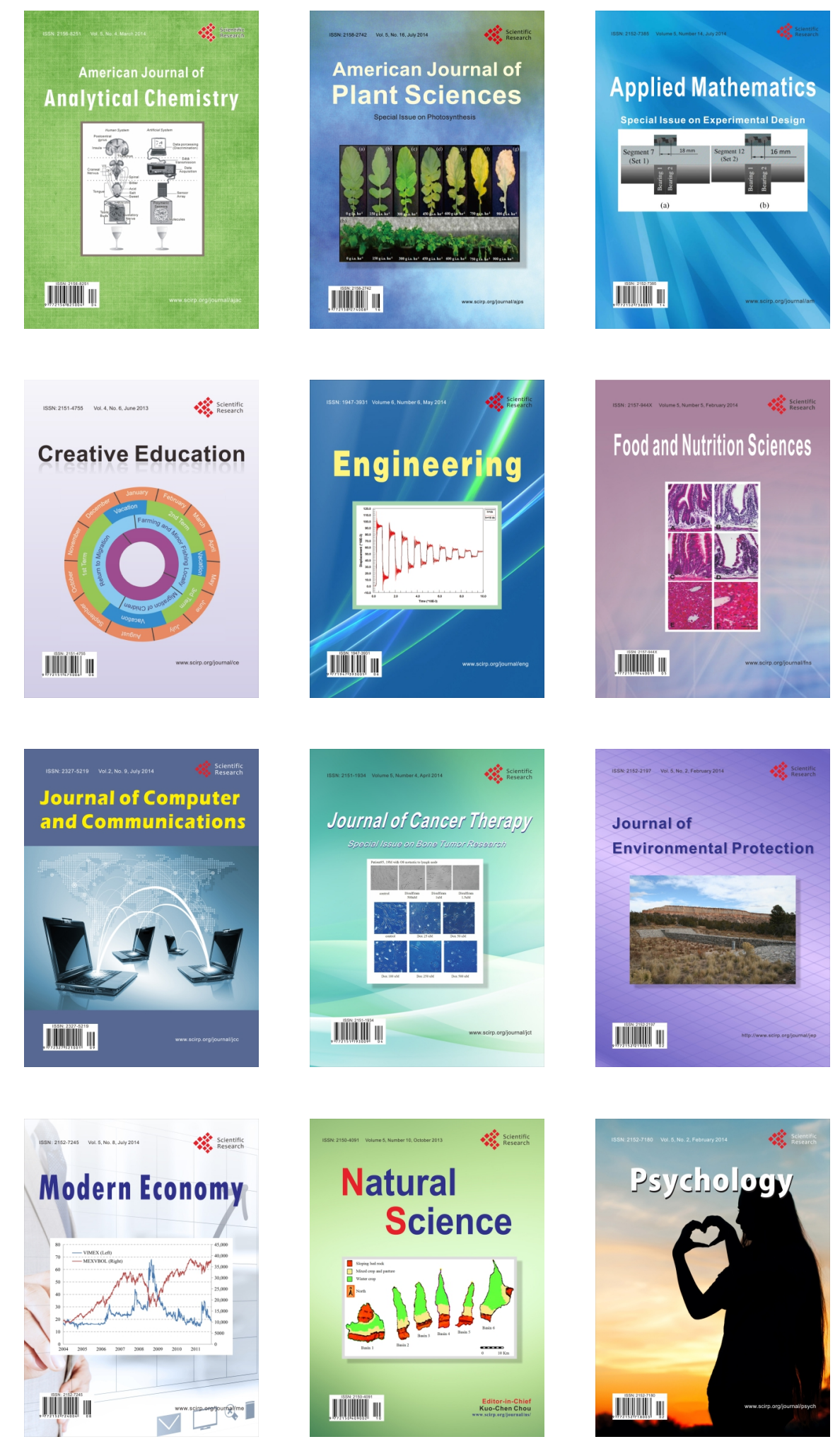